\title{
ОЦЕНКА БЕЗОПАСНОСТИ ВОДЫ СКЛЮИХИНСКОГО ВОДОХРАНИЛИЩА ПО МИКРОБИОЛОГИЧЕСКИМ И ГИДРОХИМИЧЕСКИМ ПОКАЗАТЕЛЯМ
}

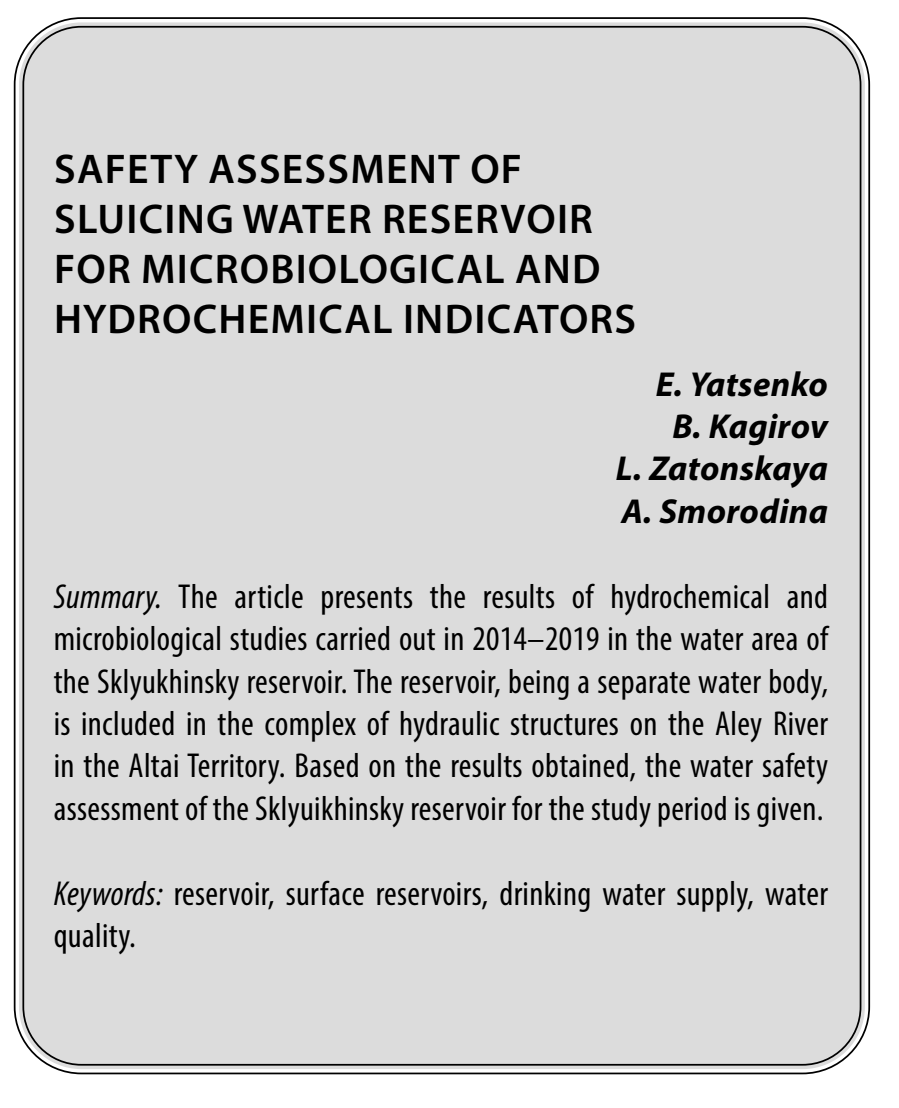

$\mathbf{M}$ ониторинг качества воды поверхностных водоемов, в том числе водохранилищ, по микробиологическим и гидрохимическим показателям является обязательным условием обеспечения безопасности источников питьевого водоснабжения. Большое количество научных исследований, посвященных оценке качества вод водохранилищ, подтверждают актуальность исследования $[1,2,3]$.

Водохранилища это искусственно созданные долинные, котловинные и естественные озерные водоемы с замедленным водообменом, полным объемом более 1 млн. м², уровень воды в которых регулируется гидротехническими сооружениями в целях накопления и последующего использования запасов и для удовлетворения хозяйственных и социальных потребностей [1]. Водохранилищам присуща особая система внутриводоемных процессов: гидрологические, гидрохимические и гидробиологические процессы имеют значительные отличаются природных водоемов [2].

\author{
Яценко Елена Сергеевна \\ К.б.н., дочент, Алтайский государственный \\ университет \\ mlprx@mail.ru \\ Кагиров Баймухамат Нуруллович \\ К.ф.н., дочент, Алтайский государственный \\ университет \\ Затонская Лина Викторовна \\ К.х.н. дочент, Алтайский государственный \\ университет \\ Смородина Анна Вадимовна \\ Алтайский государственный университет
}

Аннотация. В статье представлены результаты гидрохимических и микробиологических исследований, выполненных в 2014-2019 гг. на акватории Склюихинского водохранилища. Водохранилище, являясь обособленным водным объектом, включено в комплекс гидротехнических сооружений на реке Алей в Алтайском крае. На основании полученных результатов дана оценка безопасности воды Склюихинского водохранилища за период исследования.

Ключевые слова: водохранилище, поверхностные водоемы, питьевое водоснабжение, качество воды.

Склюихинское водохранилище является частью гидротехнического комплекса на реке Алей в Алтайском крае, куда помимо него входят Гилевский гидроузел, подпорная плотина у с. Веселоярска, подпорное сооружение у Рубцовска. Склюихинское водохранилище обособленный объект (водоем), не входящий в состав основного водозаборного гидроузла.

Начало строительства водохранилища - 1971 год. Заполнение водохранилища началось весной 1977 г. и было закончено в 1978 г. В эксплуатацию введено 1979 году. Склюихинское водохранилище наливное, без боковой проточности, образовано путем одамбирования части русла и поймы протоки Склюиха, с примыканием восточной частью к коренному берегу. Поверхностный сток протоки пропускается по обводному каналу (искусственному руслу). Боковая проточность со стороны коренного берега перехватывается и отводится напорным каналом в протоку Склюиху выше водохранилища. Наполняется водохранилище за счет 
принудительной подачи воды из реки Алей насосной станцией Рубцовского водозаборного гидроузла в летне-осенней период [4].

При наивысшем подпорном уровне верхнего бьефа объем водохранилища - 38,6 млн. м², площадь 5,82 км² $^{2}$ уровень воды - 222,50 м. абс. При наинизшим уровне воды в водохранилище, который дает возможность нормальной эксплуатации гидротехнического сооружения, объем водохранилища - 8,0 млн. м ${ }^{3}$ площадь- 5,15 км²; уровень воды - 217 м. абс [4].

Назначение Склюихинского водохранилища - резервный источник водоснабжения города Рубцовска.

Емкость водохранилища определена с учетом его назначения:

- создание резерва объемом 13,7 млн. м для водоснабжения города Рубцовска питьевой воды в период прохождения весеннего половодья на р. Алей;

- создание резервного объема 13,2 млн. м³ питьевой воды с использованием его для водоснабжения города Рубцовска в зимний период в случае перемерзания реке Алей в маловодные годы с суровой зимой.

Забор воды из водохранилища производится в апреле - июне месяцах у отметки 217,20 м. В июле, за счет естественных потерь, уровень воды в водохранилище опускается до отметки - 217,00 м. В августе - сентябре производится заполнение водохранилища до требуемых отметок [6].

Наполнение водохранилища происходит за счет принудительной подачи воды насосной станцией из реки Алей. Поступление поверхностных вод в водохранилище отсутствует. Перелив за счет переполнения емкости водохранилища невозможен. Вероятности опасных для плотины размывов в нижнем бьефе нет в связи с отсутствием паводковых водосбросов. Во избежание прогрева воды и образования мелких водорослей при низких уровнях воды, время между окончанием подачи воды на водоснабжение и новой закачкой воды в водохранилище не превышать один месяц. За время эксплуатации не наблюдалось выхода грунтовых вод на низовой откос, промерзание откоса и образования наледей, выноса грунта тела плотины через дренаж, нет очагов размыва откоса наклонного дренажа поверхностными водами [3].

Водохранилище имеет санитарную водоохранную зону шириной 500 метров уреза воды. В пределах водоохранной зоны устанавливается прибрежная полоса шириной 55 м [6].
В месте расположения водохранилища примыкающая территория с запада - плоская равнина, частично заболочена, с выходами на поверхность солончаков, не имеет древесной растительности. С восточной стороны (справа от русла) примыкает коренной берег высотой до 20 м средней крутизны. Примыкающие к протоке земли обводненные, местами засоленные поверхности и заболоченные.

Поскольку, Склюихинское водохранилище - это резерв для питьевого водоснабжения города Рубцовска, вода в нем, должна быть безопасной по гидрохимическим и микробиологическим показателям.

Безопасность питьевой воды в эпидемическом отношении определяется ее соответствием нормативам по микробиологическим показателям: ОМЧ (общее микробное число), ОКБ (общие колиформные бактерии), ТКБ (термотолерантные колиформные бактерии), споры сульфитредуцирующих клостридий и колифаги.

Общее микробное число возрастает при поступлении в водуливневых, бытовых и промышленныхсточных вод. Микроорганизмы семейства Enterobacteriaceae, указывает на загрязнение воды в широком смысле, также ОКБ свидетельствует об органическом загрязнении антропогенного происхождения. Показателем свежего фекального загрязнения воды является содержание термотолерантных колиформных бактерий Escherichia coli (ТKБ). Присутствие в воде колифагов является показателем вирусного загрязнения питьевой воды. На давнее фекальное загрязнение воды, указывает наличие в спор сульфитредуцирующих клостридий. Споры $\mathrm{Cl}$. perfringens выживают в воде дольше, чем бактерии, они устойчивы к химическим и физическим факторам среды [7].

К биогенным веществам, содержащимся в воде, относится азот. В процессе нитрификации, В аэробных условиях, аммиак окисляется до нитритов и нитратов. Нитриты - неустойчивые компоненты природных вод. Увеличение концентрации аммиака и нитритов указывает на неблагоприятное состояние водоема, не завершенный процесс нитрификации. Повышенное содержание нитратов указывает на ухудшения санитарного состояния водоема, так же свидетельствует о завершении нитрификации [8].

Гуминовые кислоты - это часть органического вещества природных вод, их повышенное содержание может отрицательно влиять на развитие водных растительных и животных организмов в результате резкого снижения концентрации растворенного кислорода в водоеме, который идет на окисление. Показателем содержания в воде органических загрязнителей, к ко- 
Таблица 1. Качество воды Склюихинского водохранилища в 2014-2019 гг. по гидрохимическим показателям

\begin{tabular}{|c|c|c|c|c|c|}
\hline \multirow[b]{2}{*}{ год } & \multicolumn{5}{|c|}{ Среднее значение показателя (за год) } \\
\hline & $\begin{array}{l}\text { Водородный } \\
\text { показатель (ед.рH) }\end{array}$ & $\begin{array}{l}\text { Аммиак } \\
\left(\text { мг\дм }{ }^{3}\right)\end{array}$ & $\begin{array}{l}\text { Нитриты } \\
(\text { мг\дм³ })\end{array}$ & $\begin{array}{l}\text { Нитраты } \\
(\text { мг\дм³ })\end{array}$ & $\begin{array}{l}\text { Перманганатная } \\
\text { окисляемость } \\
\left(\mathrm{MrO}_{2} \backslash \text { дм }^{3}\right)\end{array}$ \\
\hline 2014 & 8,09 & $<0,05$ & $<0,02$ & 0,66 & 2,9 \\
\hline 2015 & 7,69 & $<0,05$ & $<0,02$ & 2,66 & 2,7 \\
\hline 2016 & 8,21 & $<0,05$ & $<0,02$ & 0,99 & 3,0 \\
\hline 2017 & 7,98 & $<0,05$ & $<0,02$ & 2,29 & 2,9 \\
\hline 2018 & 8,05 & $<0,05$ & $<0,02$ & 1,25 & 3,1 \\
\hline 2019 & 8,20 & 0,0062 & $<0,02$ & 1,10 & 3,0 \\
\hline
\end{tabular}

Таблица 2. Качество воды Склюихинского водохранилища в 2014-2019 гг. по показателям ОКБ и ТКБ

\begin{tabular}{|c|c|c|c|c|c|c|}
\hline \multirow[b]{2}{*}{ год } & \multicolumn{3}{|c|}{ ОКБ (КОЕ\100мЛ) } & \multicolumn{3}{|c|}{ ТКБ (КОЕ\100мЛ) } \\
\hline & $\begin{array}{l}\text { Среднее } \\
\text { значение }\end{array}$ & $\begin{array}{l}\text { Максимальное } \\
\text { значение }\end{array}$ & $\begin{array}{l}\text { Минимальное } \\
\text { значение }\end{array}$ & $\begin{array}{l}\text { Среднее } \\
\text { значение }\end{array}$ & $\begin{array}{l}\text { Максимальное } \\
\text { значение }\end{array}$ & $\begin{array}{l}\text { Минимальное } \\
\text { значение }\end{array}$ \\
\hline 2014 & 8 & 24 & 1 & 7 & 24 & 1 \\
\hline 2015 & 2 & 3 & 1 & 2 & 3 & 1 \\
\hline 2016 & 3 & 3 & 3 & 2 & 3 & 1 \\
\hline 2017 & 3 & 5 & 1 & 3 & 5 & 1 \\
\hline 2018 & 3 & 4 & 1 & 1 & 1 & 1 \\
\hline 2019 & 8 & 18 & 1 & 1 & 2 & 1 \\
\hline
\end{tabular}

Таблица 3. Качество воды Склюихинского водохранилища в 2014-2019 гг. по показателям споры сульфитредуцирующих клостридии и колифаги

\begin{tabular}{|l|l|l|l|l|l|l|}
\multicolumn{7}{|l|}{$\begin{array}{l}\text { Споры сульфитредуцирующих клостридии } \\
\text { (КОЕ/2Омл) }\end{array}$} \\
\cline { 2 - 7 } & $\begin{array}{l}\text { Среднее } \\
\text { значение }\end{array}$ & $\begin{array}{l}\text { Максимальное } \\
\text { значение }\end{array}$ & $\begin{array}{l}\text { Минимальное } \\
\text { значение }\end{array}$ & $\begin{array}{l}\text { Креднее } \\
\text { значение }\end{array}$ & $\begin{array}{l}\text { Максимальное } \\
\text { значение }\end{array}$ & $\begin{array}{l}\text { Минимальное } \\
\text { значение }\end{array}$ \\
\hline 2014 & 6 & 12 & H/O & 3 & 5 & H/O \\
\hline 2015 & 1 & 2 & H/O & 1 & 1 & H/O \\
\hline 2016 & 6 & 19 & H/O & 1 & 2 & H/O \\
\hline 2017 & 3 & 6 & 2 & H/O & 1 & H/O \\
\hline 2018 & 1 & 4 & H/O & H/O & 1 & H/O \\
\hline 2019 & 2 & 3 & H/O & H/O & 2 & H/O \\
\hline
\end{tabular}

Примечание: Н/о - не обнаружено

торым относятся гуминовые кислоты является перманганатная окисляемость [9].

В связи с выше сказанным, цель работы - проанализировать качества воды Склюихинского водохранилища по микробиологическим и гидрохимическим показателям в 2014-2019 гг.

Оценка качества воды Склюихинского водохранилища проводилась по среднегодовым показателям: $\mathrm{pH}$, аммиак, нитриты, нитраты, перманганатная окисляе- мость, ОКБ, ТКБ, споры сульфитредуцирующих клостридий, колифаги. Исследование проводились в аккредитованной лаборатории МУП «Рубцовский водоканал». Все анализы выполнены в полном соответствии с нормативными документами. Отбор проб производился ежедневно в апреле, мае и июне в 2014-2019 гг.

Результаты исследования качества воды Склюихинского водохранилища по гидрохимическим и микробиологическим показателям представлены в следующих таблицах. 
Водородный показатель за период исследования изменяется не значительно (с 7,96 до 8,21 ед. рН), что советует фоновым показателя в водах реки Алей. Изменение рН в водах р. Аллей с 2014 по 2019 гг. не значительное, зависит от водности, и изменняется от 7, 2 до 8, 2 ед. рН. Содержание аммиака, нитритов и нитратов минимально (ниже предела обнаружения), что указывает на отсутствие поступления загрязнений в водоём, т.к. он изолирован от других водных объектов. Перманганатная окисляемость не высокая (в среднем - 3,0 мгО $2 /$ дм $^{3}$ ), что свидетельствует о не большом количестве гуминовых веществ в воде (ПДК для питьевой воды $5 \mathrm{mrO}_{2} /$ дм $^{3)}$ (табл. 1).

Содержание общих и термотолерантных колиформных бактерий в воде не значительно (в среднем от 8 до 2 KOE/100мл). Это указывает на отсутствие как свежего фекального загрязнения, так и постоянного загрязнений вод. Максимальные значение численности как ОКБ, так и ТКБ (24 КОЕ/100мл) отмечены в 2014г (табл. 2).
Содержание спор сульфитредуцирующих клостридий не велико (от 19 (КОЕ 20мл) до не обнаружено). Максимально значение в 2016г (19 (KOE\20мл).

Количество колифагов в воде низкое, что свидетельствует об отсутствии колиформных бактерий, на которых паразитируют фаги. Максимальное значение колифагов в 2014г, что связано с самим высокими за весь период исследования ОКБ и ТКБ (табл. 3).

На основании вышеизложенного можно сделать вывод: гидрохимические и микробиологические исследования, выполненные в мае-июле 2014-2019 гг. показали, что в Склюихинском водохранилище: $\mathrm{pH}$ советует фоновому значению в водах реки Алей, низкое содержание биогенных элементов, колиформыных бактерий, спор сульфитредуцирующих клострий и колфагов указывают на отсутствие загрязнений. Следовательно, воды Склюихинского водохранилища, могут выступать безопасным запасным источником питьевой воды для города Рубцовска.

\section{ЛИТЕРАТУРА}

1. Авакян А.Б., Салтанкин В.П., Шарапов В.А. Водохранилища (Природа мира). Москва: Изд-во “Мысль”; 1987.

2. Приказ Минприроды РФ от 26.01.2011 N17 06 утверждении Методических указаний по разработке правил использования водохранилищ. Методические указания по разработке правил использования водохранилищ.

3. Яценко Е.С., Анисимова Д.А. Оценка последствий гидродинамической аварии на Склюихинском водохранилище по имитационным параметрам волны прорыва плотины. Известия Алтайского государственного университета. Барнаул: 2014; 3-2 (83): 140-143.

4. Декларация безопасности гидротехнических сооружений. Склюихинское водохранилище на протоке (клюиха (река Алей) в Рубцовском районе Алтайского края. Книга 1. Барнаул: 2002.

5. Склюихинское водохранилище — чаша с красными каменными берегами [Электронный ресурс] URL https://lastochkanata.livejournal.com/27149.html (дата обращения 01.08.20).

6. Правила эксплуатации Склюихинского водохранилища на протоке Склюиха (река Алей) в Рубцовском районе Алтайского края. Книга 3. Барнаул; 2002.

7. Игнатьева Л.П. Критерии качества воды поверхностных и подземных источников. Эколого-гигиеническая оценка качества питьевой воды, воды водоемов: учебное пособие. Иркутск: ИГМУ; 2014.

8. Орлова Т.Н., Базлов Д.А., Орлов В.Ю. Химия природных и промышленных вод: учеб. пособие. Ярославль: ЯрГУ; 2013.

9. Сибагатуллина А.М., Мазуркин П.М., Измерение загрязнённости речной воды (на примере малой реки Малая Кокшага). Москва: Академия естествознания; 2009.

\footnotetext{
( Яценко Елена Сергеевна ( mlprx@mail.ru ), Кагиров Баймухамат Нуруллович,

Затонская Лина Викторовна, Смородина Анна Вадимовна.

Журнал «Современная наука: актуальные проблемы теории и практики»
} 